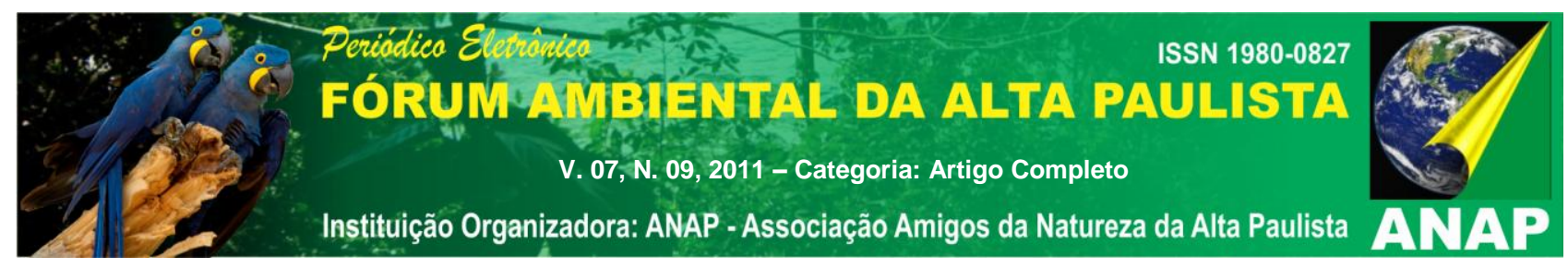

\title{
POTENCIAL TURÍSTICO DO MUNICÍPIO DE PALMEIRA-PR NA PERSPECTIVA DA ROTA DOS TROPEIROS
}

\section{Dieniffer Taline Schnell ${ }^{1}$}

\author{
Adriana Senetra ${ }^{2}$
}

\begin{abstract}
Resumo: Este trabalho tem como objetivo descrever e analisar o potencial do município de Palmeira - PR para o Projeto Regional Rota dos Tropeiros, criado a partir do Programa Nacional de Regionalização do Turismo. A cidade em tela se apresenta com um cenário rico em potencial desde no que diz respeito aos seus aspectos naturais quanto na histórico-cultural, que deve ser mais bem explorado para o turismo na cidade, contribuindo para o desenvolvimento sustentável da região e, consequentemente da Rota dos Tropeiros.
\end{abstract}

Palavras chave: Potencial Turístico, Palmeira - PR, Rota dos Tropeiros.

\section{APRESENTAÇÃO}

Conhecida como a "cidade clima do Brasil", a cidade de Palmeira cristaliza em seu espaço marcas de um passado recheado de riquezas culturais e históricas dignas de serem desvendadas. Seu potencial turístico pode ser usado no Projeto Regional Rota dos Tropeiros, visando desenvolver turisticamente e contribuindo para um desenvolvimento sustentável da região. Portanto, este trabalho tem como objetivo descrever e analisar o potencial do município de Palmeira PR dentro da perspectiva da Rota dos Tropeiros a partir de analise do historio do município, bem como a partir de sites

\footnotetext{
${ }^{1}$ Licenciada em Geografia e Mestranda em Gestão do Território pela Universidade Estadual de Ponta Grossa dieniffertalineschnell@hotmail.com

${ }^{2}$ Licenciada em Geografia pela Universidade Estadual do Centro Oeste adri cody@hotmail.com
} 


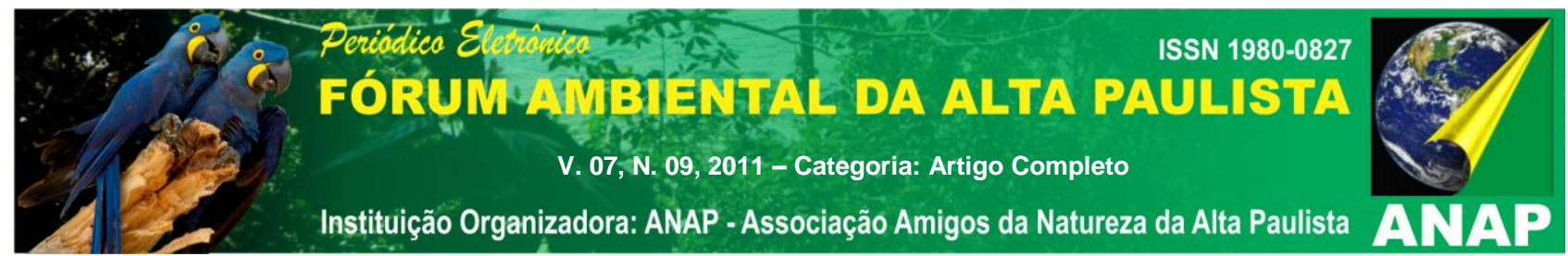

relacionados a temática turística como o Explore Brasil, que por finalidade especifica selecionar e divulgar os municípios e seus atrativos turísticos via internet, e o site da prefeitura municipal, a fim de entender como o município vem sendo divulgado neste mundo da informatização, através da internet e qual é o relacionamento do município, através do potencial turístico, exposto por esses meios, e o Projeto Regional Rota dos Tropeiros difundido na Região do Campos Gerais.

\section{1- Palmeira - cidade clima do Brasil}

Palmeira, por possuir um grande potencial turístico, aparece em diversos sites de internet, como uma parte integrante e de extrema importância nos roteiros turísticos paranaenses, juntamente com cidades de renome no âmbito cultural como, por exemplo, a cidade da Lapa.

No site explore Brasil (2011), um dos mais importantes do país no que tange a destinos turísticos nacionais, temos a divulgação abaixo sobre o que podemos encontrar em Palmeira:

Considerada a cidade clima do Brasil, em Palmeira pode-se fazer um proveitoso passeio histórico e cultural, onde os visitantes podem desfrutar de um clima ameno, belezas naturais, tranqüilidade, e hospitalidade de sua gente. Em suas ruas, praças e recantos o turista encontra a história de um povo, que tem suas raízes no tropeirismo e na imigração. Um exemplo disso está nos detalhes arquitetônicos, na natureza, na tranqüilidade das ruas, no colorido de suas praças, nas igrejas construídas em estilo barroco colonial, as capelas. A história está presente nos acervos do Museu Histórico Municipal, no Museu Étnico e Histórico da Colônia Witmarsum, na Chácara Museu representativa da etnia Russo-Alemã e no Museu do Artesanato Nacional, na Colônia Santa Bárbara. Ainda destacam-se como atrativos turísticos da região: a Colônia Cecília formada por imigrantes italianos com ideais anarquistas.(EXPLOREBRASIL, 2009)

A partir dessa pode-se perceber a riqueza que poderá ser encontrada nesse município, que localiza-se a $70 \mathrm{~km}$ de Curitiba, situada na região dos campos gerais, na microrregião de Ponta Grossa (FIGURA 1). 

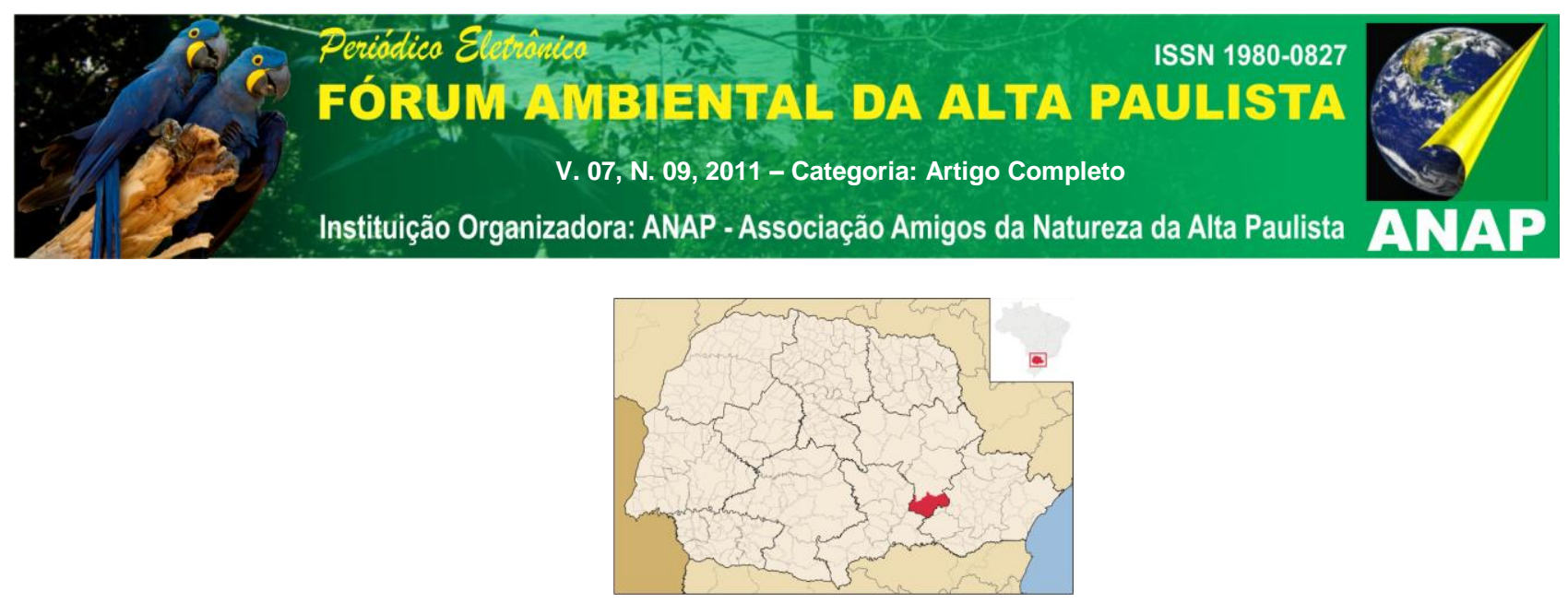

Figura 01: Localização de Palmeira - PR no Estado do Paraná.

O nascimento da cidade de Palmeira esta totalmente atrelado a passagem Rota dos Tropeiros, também conhecida como Caminho de Viamão, e/ou ainda Caminho das Tropas, que iniciou-se entre o período de 1730 e 1732, devido ao desenvolvimento do comércio de grande porte em diversas regiões do país, neste caso, a região abrangente ia de Rio Grande do Sul a São Paulo.

Durante o decorrer desse percurso, os tropeiros tinham dificuldades com as necessidades básicas, entendendo que no inicio desse ciclo, o Paraná não era totalmente habitado, e tinham-se graves problemas com a falta de estrutura como para pouso e alimentação, sendo, que grandes partes dos pernoites eram feitos em acampamentos. Com o passar do tempo, muitos dos tropeiros passaram a povoar a região abrangente pela rota. Consequentemente, através da movimentação incessante de pessoas, passou a atrair demais pessoas, dando origem a vilarejos que em seguida evoluíram à distritos e cidades.

Devido às condições favoráveis, como o clima e vegetação, que serviram como pastagens, na região dos Campos Gerais, os tropeiros encontravam uma realidade diferenciada, desta maneira, o tropeirismo proporcionou a essa região um grande avanço territorial, originando por ocasião da Rota dos Tropeiros, inúmeras cidades de grande importância para o Estado, como expressa Arantes (2000):

Com o avanço da economia tropeira, os Campos Gerais foram totalmente conquistados. Como consequências desta conquista surgiram vários núcleos populacionais, principalmente ao longo do traçado original do Caminho do Viamão. Esses núcleos se transformaram em importantes cidades como: Rio Negro, Campo do Tenente, Lapa, Porto Amazonas, Palmeira, Ponta Grossa, Castro, Piraí do Sul, Jaguariaiva e Sengês. (ARANTES in RODRIGUES, 2000, p. 390) 


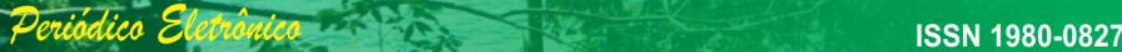

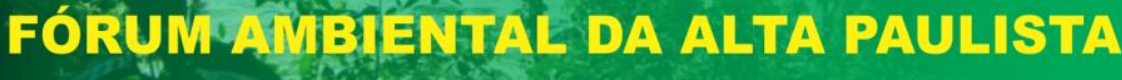 \\ V. 07, N. 09, 2011 - Categoria: Artigo Completo \\ Instituição Organizadora: ANAP - Associação Amigos da Natureza da Alta Paulista}

Desta forma, uma das cidades fundadas pela influencia da Rota dos Tropeiros, foi o município de Palmeira. Além da influencia em sua fundação o Caminho de Viamão, por muito tempo foi à perspectiva econômica visada pelo município.

Através da passagem dos tropeiros por Palmeira, atrai muitas pessoas, pela oportunidade econômica para criação de infra estrutura para a manutenção da rota, como pousadas, dando inicio, as demais atividades ligadas a criação de gado, criando-se assim um povoado que era localizado até então, em território da Freguesia de Tamanduá, juntamente com as varias cidades da região. Em 1823 é transferida oficialmente para Freguesia Nova de Nossa Senhora da Conceição de Palmeira, nome dado em virtude da Construção da Igreja Matriz Nossa Senhora da Conceição, padroeira do local.

No período de 1877 passa a ser legalmente considerada como cidade, porém, teve consolidação somente em 1878 com a chegada dos imigrantes europeus que aos poucos se instauraram na região.

\section{2- $\quad$ Arquitetura e Potencial Turístico.}

Em questões arquitetônicas, Palmeira conta com rico acervo cultural de museus, igreja, residências e demais elementos urbanos e rurais que conservam uma arquitetura com grande influencia europeia obtido com os fluxos imigratórios do período colonial.

Observando os principais monumentos e demais edificações concretizadas no espaço urbano e rural do município em questão, pode-se enfatizar os antigos casarões das colônias rurais e das fazendas, devido ao seu grande teor histórico, bem como, destacando a cultura e edificações religiosas determinando para cada templo religioso uma característica física, determinada pelo período de construção e da sociedade participante devido suas histórias, através da própria cultura local, trazendo a população toda a relação de sentimentalidade e simbolismo perante a população. Neste sentido também deve-se trazer os demais elementos que são determinantes importantes ao município e se caracteriza como atrativos turísticos do município, tanto relacionados a questão popular, quanto aos mais diversos sites que tratam do assunto, abordando as praças, museus e os inúmeros potenciais turísticos não só na área urbana, como também, na área natural como cavernas com espeleotemas e belas paisagens naturais, que caracterizam o Patrimônio Natural da cidade.

Entre os principais monumentos arquitetônicas citados destacam-se: 
a) Praça Marechal Floriano Peixoto: Praça arborizada ainda durante o governo Imperial que abriga um antigo chafariz;

b)Fazenda da Conceição: Construção do Século XVIII em estilo colonial, feita em taipa e estuque;

c) Fazenda Palmeira: Pertenceu ao fundador da cidade teve seu nome originado pela presensa de uma enorme Palmeira dentro da propriedade;

d) Fazenda Padre Inácio: Construção do Século XVII, feita pelos carmelitas;

e) Fazenda da Baronesa: Construção do Século XVIII onde se preserva traços arquitetônicos muito interessantes, atualmente abriga uma unidade do Exército;

f) Igreja da Nossa senhora da Imaculada Conceição: Construída em 1837 e tem como características arquitetônicas o estilo barroco-colonial;

g) Capela do Senhor Bom Jesus: Construção ao estilo barroco colonial datada de 1836, possui um cemitério em anexo;

h) Capela de Nossa senhora das Neves: Construção de 1880, servia como pouso para os tropeiros. Possui dois sinos de Bronze e algumas grutas com formações de estalactites;

i) Museu Histórico: Criado em 1977 encontra se instalado em um solar tombado pelo departamento histórico e artístico;

J) Sítio Minguinho: Um excelente local para lembrar como era a vida na década passada, constituindo um "museu ao ar livre".

Como principais potenciais de turismo natural em Palmeira temos:

a) Grutas do Cercado: Ficam na localidade de Cercado, uma região com escarpas, matas e campos de transição. As grutas possuem belos espeleotemas;

b) Mirante do Cercado: o mirante é descrito como uma atração imperdível da região, pois deles podemos observar do vale formado abaixo, assim como observamos as diversas macro feições do relevo;

c) Represa do salto: Localizada no rio do salto atrai centenas de pessoas nos dias quentes. Possui varias quedas de água e espaço para acampamentos;

d) as Estrias Glaciais: localizadas na Colônia de Witmarsun, foram formadas pelo movimento de geleiras durante o período da glaciação (Permo-Carbonifera), cerca de 300 milhões de anos atrás. 


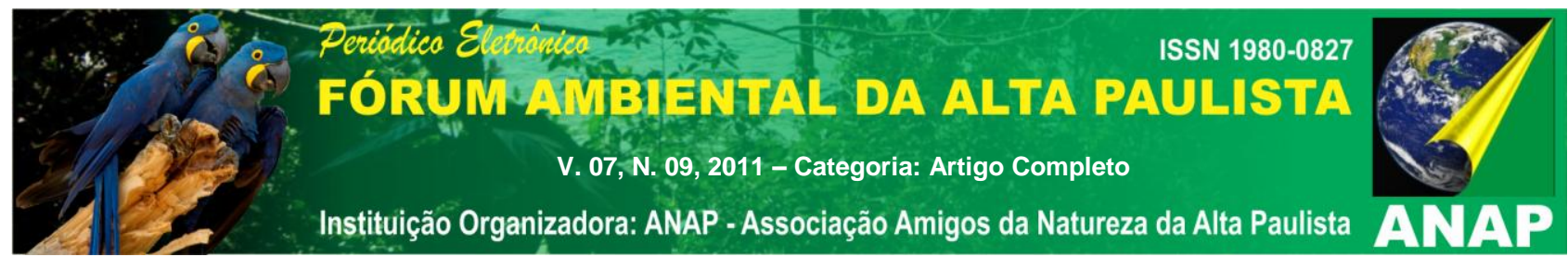

Assim podemos transcrever Palmeira, a cidade "clima do Brasil", que cristaliza no espaço urbano e rural de sua cidade as mais diversas atrações dignas de participar do Projeto Regional Rota dos Tropeiros e demais projetos turísticos que poderão vir.

\section{3- O Projeto Regional Rota dos Tropeiros e o municipio de Palmeira:}

Dentro da perspectiva do Plano Nacional do Turísmo 2004-2007 e de seu sucessor 2007-2010, surge a intenção de criar um Programa que valorizasse todas as Rotas de grande importancia, que ja existiram ou ainda existem no Brasil. Desta forma surge o Projeto Nacional Roteiros do Brasil.

Este projeto baseia-se em um Programa de Regionalização do Turismo que tem por objetivo desenvolver, através do Patrimônio Cultural e demais atrativos turísticos, as regiões que possuem rotas de grande importância para a história e para as culturas nacional e regional, dentro do território brasileiro, derivando diversos outros projetos de origem mais localizados, como o Projeto Rota dos Tropeiros na Região dos Campos Gerais.

A Rota dos Tropeiros, originado a partir desse Projeto, é desenvolvido no Estado do Paraná, através das entidades públicas e do Estado, possuindo o objetivo de buscar o desenvolvimento sustentável da região através da expansão dos aspectos turísticos da Região dos Campos Gerais, abrangendo ao todo 16 municípios.

Este projeto sustentado e coordenado pela Associação dos Municípios dos Campos Gerais (AMCG) em parceria com a Secretaria de Estado do Turismo do Paraná, Paraná Turismo, Eco-Paraná e do Sebrae-Pr, buscando propor uma espécie de, "pacote turístico", em que o visitante obtenha todas as informações, acesso, qualidade, segurança e comodidade através de serviços interligados: rotas turísticas, hospedagem, circulação, alimentação e a própria acessibilidade em torno da região e ao seu Patrimônio Cultural e Turístico da região.

Outro dos objetivos inclusos no Projeto Regional Rota dos Tropeiros, é o desenvolvimento econômico e social da região. Dentro dessa perspectiva o desenvolvimento econômico se da, através da renda que esse pacote turístico pode trazer a região, devido alimentação, no caso de restaurante e lanchonetes, de hospedagem, nos hotéis e pousadas, e dos demais produtos produzidos na região, como, por exemplo, o 
artesanato, trazendo benefícios à região não apenas relativo a geração de capital, mas também do reconhecimento pelas produções do local.

Nos aspectos sociais, o Projeto tem por objetivo o resgate da história e a memória local, relativa a Rota dos Tropeiros na busca da valorização social, trazendo a população o orgulho de pertencer a região abrangente, relativa a sua história, as suas memórias e vivencias e a sua cultura em geral.

Tendo em vista a perspectiva do Projeto "Rota dos Tropeiros", ele propende divulgar, analisar, e identificar o Patrimônio Cultural que se compõe nessa região, proporcionando desde sua origem, quando era ainda denominado como "Caminho das Tropas" até os dias atuais, desenvolvendo a região através do seu Potencial Turístico, e, também pelos seus aspectos econômicos e sociais.

\section{4- Potencial Turístico do município de Palmeira - PR na perspectiva da Rota dos Tropeiros:}

Devido base formadora e emancipadora do municipio de Palmeira estar totalmente ligada aos principios do Tropeirismo, e por muito tempo depender economicamente da Rota, esta cidade passa a possuir fundamental importancia dentro do Projeto Regional Rota dos Tropeiros, buscando também, desenvolver todo o seu potencial turistico, bem como, a sua preservação.

Atualmente, num periodo denominado por muitos autores da geografia e das areas a fins, como Pós - Moderno, busca-se através do novo promover o antigo, como percebemos a partir dos sites relacionados ao turismo, sendo que como os principais atrativos das cidades estão relacionados ao seu Patrimônio Cultural. Desta maneira, a partir da análise do site Explore Brasil, podemos confirmar através do municipio de Palmeira, que o Potencial a totalmente Turistico esta totalmente baseado em seu Patrimônio Cultural, principalmente daqueles construidos ou adquiridos com a passagem da Rota dos Tropeiros pelo municipio.

A partir dessa difusão de informações desse tipo via internet, e seus vários de acessos a história do municipio, bem como seu Patrimônio Cultural e a própria Rota dos Tropeiros, passam a ser difundidas a milhares de pessoas, não só em território nacional, como em um território global. 


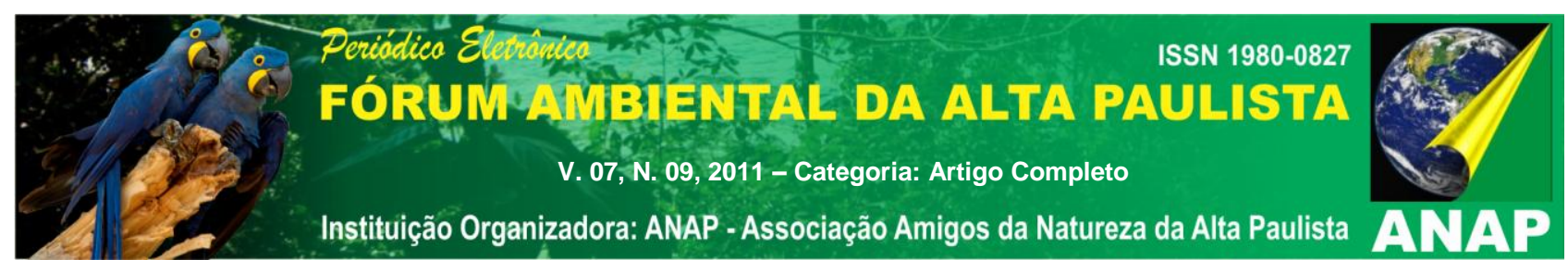

\section{5- Considerações Finais}

A busca de novas formas de divulgação e até mesmo, propagandas turísticas abrange cada vez mais os meios de comunicação, principalmente da internet das mais variadas formas possíveis, auxiliado no conhecimento, divulgação e preservação dos Patrimônios Culturais e de todos os atrativos turísticos locais, consequentemente, com a finalidade de atrair turistas as regiões e/ou municípios.

Palmeira é abordada por inumeros sites turisticos como um dos principais locais para a prática turistica dentro do território paranaense, devido ao seu acervo histórico-cultural, seja ele material, atráves das edificações, ou pelo imaterial, ou seja, pela cultura tropeira, e dos imigrantes europeus herdadas pelo municipio.

Devido a essas caracteristicas, é que Palmeira hoje faz parte do Projeto Regional Rota dos Tropeiros e busca dessa forma, identificar, preservar e divulgar todo seu potencial turistico através de todos os meios, inclusive digital.

\section{REFERÊNCIAS}

ARANTES, A. I. do B. et. Al. O tropeirismo em projetos. In RODRIGUES, E. M. S. Bom Jesus e o tropeirismo no Cone Sul. Porto Alegre: ESY, 2000. p. 387-421.

BARRETO, M. Turismo e Legado Cultural. 6. Ed. campinas: papiros, 2000.

CARARO, Iziz Felix; SOCHODOLAK, Hélio. 1890- Colônia Cecília, Uma Experiência Anarquista No Paraná. Revista Eletrônica Lato Sensu UNICENTRO. Guarapuava-PR, Ano 3, n. 1. Março de 2008

LIMONAD, E.; HAESBAERT, R. O Território em Tempos de Globalização. Revista Eletrônica de Ciências Sociais Aplicadas e outras coisas. http: //www.uff.br/etc. 15 de Agosto de 2007, $\mathrm{n}^{\circ} 2$ (4), vol. 1

MAYER, Tereza W. Memórias de Palmeira - Vol. I. Palmeira: Cidade Clima, 1996. 


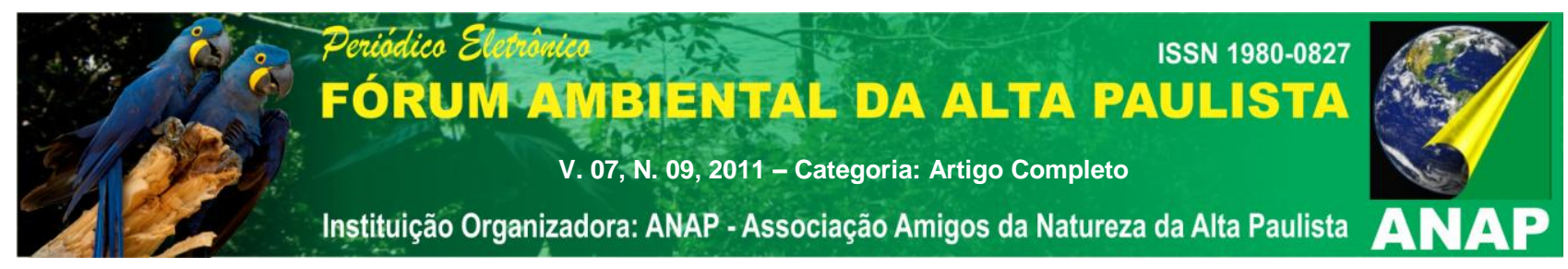

WARNIER, Jean - Pierre. A Mundialização da Cultura, Bauru: EDUSC, 2000.

EXPLORE BRASIL. Palmeira: Rota dos tropeiros. Disponível em <http://www.explorevale.com.br/rotadostropeiros/palmeira/index.htm> . Acesso em 9 de setembro de 2008.

PREFEITURA Municipal de Palmeira. Disponível em <http://www.prefeiturapalmeira.com.br/>. Acesso em 9 de setembro de 2008.

PROGRAMA NACIONAL DE MUNICIPALIZAÇÃO DO TURISMO. Disponível em http://www.abrasil.gov.br/avalppa/RelAvalPPA2002/content/av_prog/083/prog083.htm acesso em 22 de agosto de 2011. 